\title{
Editorial
}

Journal of Innate

Immunity

\section{Chasing Flies because Time Flies}

In this issue of the Journal of Innate Immunity, Rafael Cantera and Rosa Barrio [1] describe the relationship between neurodegeneration and innate immune responses in humans by referring to studies on Drosophila. At first glance, when reading the title and the abstract of the review, the reader may wonder whether the authors' conclusions are fictional. However, decades ago, pioneer work performed by Boman et al. [2] and Lemaitre et al. [3] set the fundament for this area of research, showing that the basic function of the immune system in insects evolved into the complex regulation of host defenses found in humans. So long ago, these researchers already reported that Drosophila has an inducible antibacterial defense system [2] and that Toll-like receptors regulate immunity against fungi [3]. Both findings have provided a basis for our understanding regarding critical innate defense mechanisms that are both phylum-independent and evolutionarily conserved. More recent investigations of innate defense mechanisms in Drosophila, e.g. the induction of antimicrobial peptides [4], the activation of the IMD pathway [5], antimicrobial autophagy [6] and host responses in epithelial barriers [7] are in line with these findings, supporting the concept that many principles of innate immunity in the animal kingdom originated very early on and have an important function in vertebrates still today. This also applies to the article by Cantera and Barrio [1], who present convincing evidence that in neurodegenerative processes, it is not only that the same immune genes are employed in Drosophila and Homo sapiens, but also that the transcription of these genes is regulated in a similar manner. It is therefore not surprising that the authors conclude that Drosophila can be used as an instrumental model to elucidate the role of immune response as regulators of neuroprotection.

In addition to Drosophila, much has been learnt from studying the zebrafish (Danio rerio), appearing as an early vertebrate during evolution. The zebrafish has become an important organism for exploring defense mechanisms in innate immune responses, such as in a model of Candida albicans infection [8]. The list of animal types to be studied is continuously growing and also contains more exotic species including the lophotrochozoan snail Biomphalaria glabrata [9] and the African clawed frog (Xenopus laevis) [10]. These examples show that a great deal of our knowledge about innate immune processes has been achieved by studying invertebrates and early vertebrates. However, one should not forget that invertebrates can also act as pathogens and actually cause disease. For instance, the Journal of Innate Immunity recently published that $\gamma$-tocopherol supplementation can suppress house dust mite allergies [11] or that serine proteases in the German cockroach can regulate chemokine production and dendritic cell recruitment [12]. Such interactions also contribute to increasing our knowledge about innate immunity. Together, the examples show that mechanisms of innate immunity and virulence occurred early on in the evolution of animals. Studies on invertebrates have contributed tremendously to our current understanding of the molecular mechanisms underlying host-parasite interactions.

Heiko Herwald, Lund Arne Egesten, Lund

\section{KARGER 125\%}

C) 2014 S. Karger AG, Basel

$1662-811 X / 14 / 0071-0001 \$ 39.50 / 0$ 


\section{References}

1 Cantera R, Barrio R: Do the genes of the innate immune response contribute to neuroprotection in Drosophila? J Innate Immun 2015;7:3-10.

-2 Boman HG, Nilsson I, Rasmuson B: Inducible antibacterial defence system in Drosophila. Nature 1972;237:232-235.

$>3$ Lemaitre B, Nicolas E, Michaut L, Reichhart JM, Hoffmann JA: The dorsoventral regulatory gene cassette spätzle/Toll/cactus controls the potent antifungal response in Drosophila adults. Cell 1996;86:973-983.

4 Vonkavaara M, Pavel ST, Holzl K, Nordfelth R, Sjostedt A, Stoven S: Francisella is sensitive to insect antimicrobial peptides. J Innate Immun 2013;5:50-59.

5 Karlsson J, Oldenvi S, Fahlander C, Daenthanasanmak A, Steiner H: Growing bacteria shed elicitors of Drosophila humoral immunity. J Innate Immun 2012;4:111-116.
6 Moy RH, Cherry S: Antimicrobial autophagy: a conserved innate immune response in Drosophila. J Innate Immun 2013;5:444455.

7 Davis MM, Engstrom Y: Immune response in the barrier epithelia: lessons from the fruit fly Drosophila melanogaster. J Innate Immun 2012;4:273-283.

-8 Kuo ZY, Chuang YJ, Chao CC, Liu FC, Lan $\mathrm{CY}$, Chen BS: Identification of infection- and defense-related genes via a dynamic hostpathogen interaction network using a Candida albicans-zebrafish infection model. J Innate Immun 2013;5:137-152.
$>9$ Portela J, Duval D, Rognon A, Galinier R, Boissier J, Coustau C, Mitta G, Theron A, Gourbal B: Evidence for specific genotypedependent immune priming in the lophotrochozoan Biomphalaria glabrata snail. J Innate Immun 2013;5:261-276.

10 Grayfer L, Robert J: Colony-stimulating factor1-responsive macrophage precursors reside in the amphibian (Xenopus laevis) bone marrow rather than the hematopoietic subcapsular liver. J Innate Immun 2013;5:531-542.

11 Geiser M, Lay JC, Bennett WD, Zhou H, Wang X, Peden DB, Alexis NE: Effects of ex vivo gamma-tocopherol on airway macrophage function in healthy and mild allergic asthmatics. J Innate Immun 2013;5:613-624.

-12 Day SB, Ledford JR, Zhou P, Lewkowich IP Page K: German cockroach proteases and protease-activated receptor- 2 regulate chemokine production and dendritic cell recruitment. J Innate Immun 2012;4:100-110. 